\title{
Cross-linked PEDOT: PSS as an alternative for low-cost solution-processed electronic devices
}

\author{
Renan Colucci ${ }^{\mathrm{a}, \mathrm{b}, *}$, Matheus Henrique Quadros ${ }^{\mathrm{a}}$, Flávio Henrique Feres ${ }^{\mathrm{a}}$, \\ Francisco Barbosa Maiac ${ }^{\mathrm{c}}$, Fábio Simões de Vicente $^{\mathrm{a}}$, Gregório Couto Faria ${ }^{\mathrm{b}}$, \\ Lucas Fugikawa Santos ${ }^{\mathrm{a}, \mathrm{d}}$, Giovani Gozzi ${ }^{\mathrm{a}}$ \\ a Physics Department, Institute of Geosciences and Exact Sciences, São Paulo State University - UNESP, Rio Claro 13506-900, Brazil \\ ${ }^{\mathrm{b}}$ Sao Carlos Institute of Physics, University of São Paulo, PO Box 369, 13560-970, São Carlos, SP, Brazil \\ ${ }^{c}$ Brazilian Synchrotron Light Laboratory (LNLS), Brazilian Center for Research in Energy and Materials (CNPEM), Zip Code 13083-970, Campinas, Sao Paulo, Brazil \\ d Physics Department, Institute of Biosciences, Language and Exact Sciences, São Paulo State University - UNESP, São José do Rio Preto 15054-000, Brazil
}

\section{A R T I C L E I N F O}

\section{Keywords:}

Cross-linked PEDOT:PSS

Organic semi-transparent electrodes

Organic electrochromic devices

Hybrid light-emitting diodes.

\begin{abstract}
A B S T R A C T
A number of solution-processed electronic materials have been developed for application in printed devices, which are normally built by piling up several coated layers one on the top of the other. To achieve low-cost and simple to manufacture printed devices, stable and easy to process layers are mandatory. Here we introduce a mixture of poly(3,4-ethylenedioxythiophene):polystyrene sulfonate (PEDOT:PSS) with 3-glycidoxypropyltrimethoxysilane (GPTMS) as solution-processed material that becomes insoluble in water after film processing. We performed morphological, optical and electrical characterization in the proposed composite and highlight its advantages as a stable transparent electrode in light-emitting diodes as well as in electrochromic devices.
\end{abstract}

\section{Introduction}

Soluble electronic materials have been profusely investigated in the past few years and are prone to become the system of choice in the new era of flexible electronics. The combination of easy solution processability with key electronic properties have made them great candidates for large-area and low-cost devices [1-5]. For instance, soluble materials have been successfully employed as active material in light-emitting devices, such as polymer light-emitting diodes (PLEDs) [6] and polymer light-emitting electrochemical cells (PLECs) [7], to mention a few. Recently, a new light-emitting composite was proposed, comprising a conducting polymer and an inorganic light-emitting powder to efficiently produce light-emitting devices, (known as LECEL - LightEmitting Composite Electroluminescent Device) [8]. It is well-known that light-emitting devices have to be fabricated with, at least, one transparent electrode to allow light to exit the cell efficiently. The most used transparent electrode in light-emitting devices is the indium tin oxide (ITO), which is normally coated by sputtering techniques $[9,10]$, and offers sheet resistance range of 10-100 $\Omega$ /sq and transmittance higher than $70 \%$ (at $\lambda=550 \mathrm{~nm}$ ).

One of the main challenges when producing light-emitting devices is the need of stacking several layers on the top of the other. In the simplest structures, it is necessary to intercalate the active layer between a high work function electrode and a low work function electrode to produce PLEDs $[6,11]$. However, in order to achieve highly-efficient emission from PLEDs, more complicated architectures are needed, which may involve the addition of an electron and/or hole transport layers between the electrodes and the active layers [12]. On the other hand, light-emitting devices like PLECs and LECELs present less restrictions regarding balanced electron/hole injection from the electrodes $[7,8,13,14]$, dispensing the use of work-function matched electrodes and making them appropriate candidates for the use of solutionprocessed electrodes. Recently, for instance, PLECs using graphene as bottom electrode and poly(3,4-ethylenedioxythiophene):polystyrene sulfonate (PEDOT:PSS) as top electrode have been proposed [15]. Along the same line, Liang et. al produced PLECs using silver-nanowires/single-walled-carbon-nanotubes bilayer as bottom electrode and silver-paste as top electrode [16]. These recent discoveries pushed the development of solution processed electrodes, mainly using hot materials, such as graphene, carbon-nanotubes and metallic nanostructures as active materials [15,17-27].

Reduced graphene, carbon nanotubes and metallic nanostructures are great candidates for the fabrication of semitransparent electrodes due to its highly-conductivity and chemical stability properties. However, these materials present high optical absorption in the visible range, demanding ultra-thin films to achieve high optical

\footnotetext{
* Corresponding author at: Physics Department, Institute of Geosciences and Exact Sciences, São Paulo State University - UNESP, Rio Claro 13506-900, Brazil.

E-mail address: rcolucci@usp.br (R. Colucci).
} 
transmittance. Usually, ultra-thin films are obtained by deposition techniques like spin-coating, which are not compatible with large scale production methodologies. An alternative is the use of solution-processed electrodes obtained via inkjet printing or spray-coating deposition, using semitransparent conducting polymer such as PEDOT:PSS $[17,28]$. However, being a water-soluble polymer, PEDOT:PSS based compounds are not chemically stable, especially when exposed to moisture and aqueous solution. However, on the other hand, organic/ silica hybrid materials, also known as organic modified silicates (ORMOSIL), can be prepared as high-transparent colloids, which can result in a wide variety of condensate materials, yet insulating, with high chemical stability and outstanding mechanical and optical properties; not to mention its crosslinking nature $[29,30]$.

It is well-known that water-stability and adhesion are the major problem of PEDOT:PSS film when used as conductive electrode or sensing media. Due to easy swelling, cracking-off, and dissolution of PEDOT:PSS film in water, researchers normally add cross-linkers, such as ORMOSIL, that holds the film integrity in place when interfacing PEDOT:PSS films with water solution or even when exposed to humidity. For instance, the Organic Electrochemical Transistor (OECT) and biosensing community have been using silanes for years to stabilize PEDOT:PSS film when interfacing it with biological environment [31-34].

Here we propose a new composite, which can be applied to lightemitting devices as semitransparent electrode, as well as the active layer on electrochromic devices and to produce phosphors-based electroluminescent materials. The main objective is to combine the high transparency and chemical stability of ORMOSIL materials with the enhanced conductivity of PEDOT:PSS, focusing in large scale production. We have used 3-glycidoxypropyltrimethoxysilane (GPTMS) as source of the ORMOSIL material and studied the optoelectronic and morphological properties of composites with different weight ratios between PEDOT:PSS and GPTMS. We observe different regimes of conductivity with varying GPTMS/PEDOT:PSS ratio, and provide guidelines on how conductivities and film transparency can be selected by varying the GPTMS/PEDOT:PSS ratio in the mixture as well as the composite thicknesses.

\section{Material and methods}

The highly conductive PEDOT:PSS ink was purchased from Clevios ${ }^{\mathrm{TM}}$ under the name of PH-1000. Films conductivity of up to $1000 \mathrm{Scm}^{-1}$ were produced after addition of 5\%-wt of ethylene glycol to the solution [35]. The GPTMS used in this work was provided by Sigma-Aldrich and used as is, whereas the Mn-doped zinc silicate was purchased from Fluka. The molecular structures of both materials are shown in Fig. 1. PEDOT:PSS/GPTMS solutions with PEDOT:PSS concentrations varying from $10 \%$-wt up to $100 \%$-wt (pure PEDOT:PSS) were prepared and stirred for $24 \mathrm{~h}$ at room temperature. The solutions were used to obtain films by spray coating, using a manual aerograph (Western, model AER4), onto clean glasses substrates on top of a hot plate at $40{ }^{\circ} \mathrm{C}(303 \mathrm{~K})$. A mechanical shadow mask forming films with $9.0 \mathrm{~mm}$ width was used to pattern the PEDOT:PSS film. Subsequently, the films were baked at $373 \mathrm{~K}$ for $15 \mathrm{~min}$ to eliminate solvent (water) traces. Top Au electrodes were deposited in high vacuum $\left(<10^{-6} \mathrm{mbar}\right.$ ) by thermal evaporation. Electroluminescent devices were obtained with the active layer, comprising GPTMS/PEDOT:PSS/ $\mathrm{Zn}_{2} \mathrm{SiO}_{4}: \mathrm{Mn}$ (0.045/0.005/0.95\%-wt.), deposited by drop-casting the precursor solution onto either ITO-coated glass substrates ( $50 \Omega$ /sq sheet resistance) or glass substrates coated by a GPTMS/PEDOT:PSS (50/50\%-wt) layer. After spreading the active layer solution onto the substrates, the devices were left to rest inside a furnace for $24 \mathrm{~h}$, at room temperature, to allow the silicate to sedimentate. Subsequently, the temperature was increased to $80{ }^{\circ} \mathrm{C}(353 \mathrm{~K})$ and left for $24 \mathrm{~h}$ for solvent evaporation. All films were obtained without pinholes and with good edge definition, as presented in Fig. S1 to S4 in the supplementary information (SI). The morphological a)<smiles>CC(C)(C)c1sc(C(C)(C)C)c2c1OCCO2</smiles><smiles>CC(C)(C)CC(CC(C)(C)C)c1ccc(S(=O)(=O)[O-])cc1</smiles>
PEDOT PSS

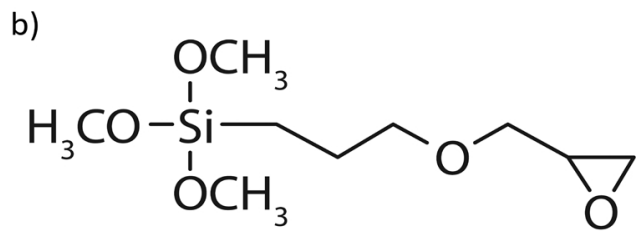

Fig. 1. Chemical structure of a) poly(3,4-ethylenedioxythiophene):polystyrene sulfonate (PEDOT:PSS) and b) 3-glycidoxypropyltrimethoxysilane (GPTMS).

characterization of the obtained films by optical microscopy, profilometry and atomic force microscopy are also presented in the SI.

\section{Results and discussion}

Fig. 2(a) and (b) present the dependence of conductivity of GPTMS/ PEDOT:PSS films on PEDOT:PSS content in the mixture (monolog and linear scales, respectively). Two regimes of conductivity can be observed in the curve, with a clear transition at $40 \%$-wt of PEDOT:PSS. Below 40\%-wt, we observe an exponential dependence of film conductivity with PEDOT:PSS content, whereas above 40\%-wt the conductivity scales linearly with the PEDOT:PSS amount. This is due to the formation of percolation paths of conductive PEDOT:PSS aggregates throughout the GPTMS matrix. For low PEDOT:PSS concentrations, the conductive aggregates do not overlap efficiently and the overall conductivity of the film is limited by hopping of mobile charges between spatially separated aggregate regions, which reduces the overall film conductivity. An evidence of the disconnected PEDOT:PSS-rich aggregates was observed in a sample containing $15 \%$-wt of PEDOT:PSS using the near-field FTIR spectroscopy microscopy, presented in Fig. S5 from supplementary information. For electrode applications, it is mandatory to be on the higher concentration regime, where percolation paths are established and conductivities are higher. However, for several other applications, such as phosphors-based electroluminescent materials, a lower overall conductivity might be needed, which can be achieved by selecting a lower PEDOT:PSS concentration in the mixture as will be discussed in the next sections.

Fig. 2(c) shows the dependence of the optical absorption coefficient of GPTMS/PEDOT:PSS films on PEDOT:PSS concentration. The shape of the absorption curve does not vary considerably with the addition of GPTMS in the composite, due to the high transparency of GPTMS in the visible spectrum. Given that the PEDOT:PSS is the only optically active material in the composite (within the analyzed energy range), the major observed change is a linear increase on the absorption intensity with increase of PEDOT:PSS content. This is better observed in Fig. 2(d), where the absorption coefficient is plotted for three different wavelengths: 599, 555 and $446 \mathrm{~nm}$ (in the blue, green and red ranges of the visible spectrum). Fig. 2 as a whole forms the basis to build a figure of merit that relates the sheet resistance, light transmitance and cost of production of the conductive composite here presented. The results are summarized in Fig. 3(a). A similar curve was already published by Carr et. al. and further details on its construction can be found in reference 

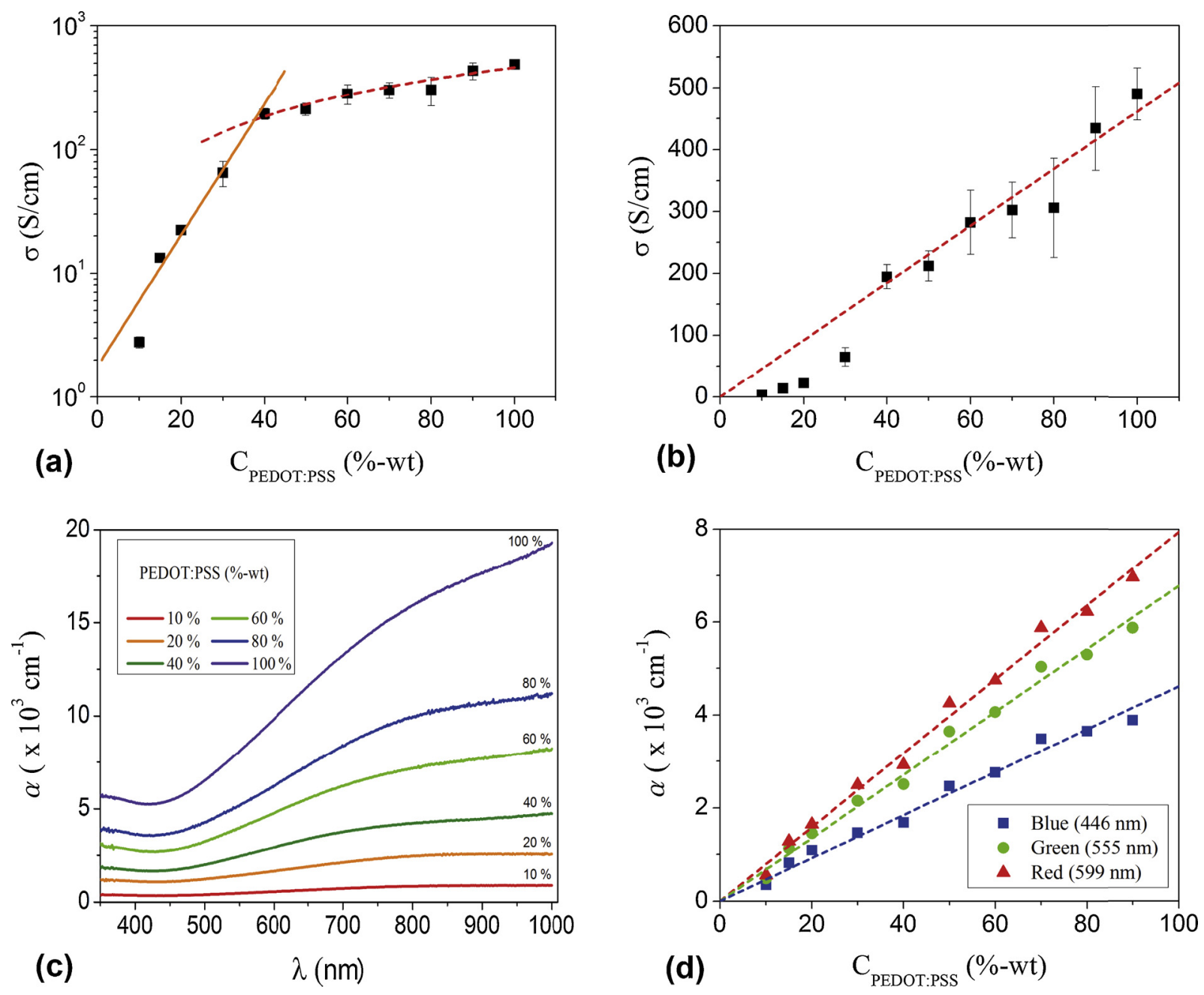

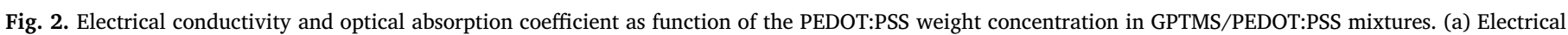

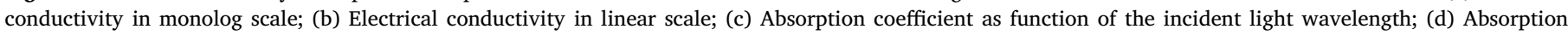
coefficient as function of the PEDOT:PSS weight ratio at specific wavelengths.

[28]. The diagram in Fig. 3(a) evidences the limits in optical transmittance and sheet resistance, with dashed lines representing the film characteristics at a specific film thicknesses, and solid lines representing the behavior at constant PEDOT:PSS concentrations. This figure of merit is suitable to dictate guidelines to produce films of GPTMS/ PEDOT:PSS for application as semitransparent electrodes. For reference, we also added on the chart the mean position of commercial ITO (Sigma-Aldrich Indium tin oxide, reference number 639281 and 576352). Here we are not considering the production cost of an ITO film, as it would be way far out in the current chart. The commercial ITO sits almost on the top of $0.5 \mu \mathrm{m}$ thickness and 50\%-wt PEDOT:PSS reference curves. Therefore, similar ITO electrodes performance can be achieved using the strategy reported here at a lower production cost. Additionally, in the supplementary information (Fig. S6) we present figures of merit obtained for samples produced with a mixture of PEDOT:PSS and GPTMS:tetraethyl orthosilicate (TEOS) as the transparent phase and cross-linker agent.

It is worthwhile mentioning that the addition of GPTMS in PEDOT:PSS solution also enhanced the film stability in aqueous environment. Fig. S7 presents the changing of relative absorbance over time of water-soaked pure PEDOT:PSS and crosslinked GPTMS/ PEDOT:PSS films. Normally, a decrease in the relative absorption is associated with losses in the film mass. It can be seen from Fig. S7 that pure PEDOT:PSS film dissolves in a matter of minutes when immersed in water. However, for crosslinked GPTMS/PEDOT:PSS the relative absorption remains almost unvaried, indicating high stability of the films in aqueous environment. The most accepted cross-linking reaction between PEDOT:PSS and GPTMS occurs between the sulfonate groups $\left(-\mathrm{SO}_{3}{ }^{-}\right)$present in the excess of PSS and the epoxy ring of GPTMS. As for the methoxysilane group found also in the GPTMS, they are more likely to bond either to the methoxysilane group of another GPTMS molecule or to the glass substrate [36].

As a proof of concept, we connected two $3 \mathrm{~V}$ batteries in series with a LED and a film $10 \times 10 \mathrm{~cm}$ GPTMS/PEDOT:PSS (50/50\%-wt) onto a glass substrate. The picture in Fig. 3(b) illustrate the conductivity and transparency that can be achieved with the current strategy when producing GPTMS/PEDOT:PSS electrodes. To show the flexibility of the films, Fig. 3(c) displays a picture of a film coated onto polyethylene terephthalate (PET) substrate in front of a small light bulb.

In order to test such material in practical applications, we experimented them as component in a phosphors-based electroluminescent material, as shown in Fig. 4. Devices were produced by mixing the GPTMS/PEDOT:PSS (90/10\%-wt) composite as conductive matrix with $\mathrm{Zn}_{2} \mathrm{SiO}_{4}: \mathrm{Mn}$ microparticles as light-emitting phase. Even though the mechanisms to convert the electric energy to light in this class of materials are not completely understood, functional devices were obtained using non-percolated conductive matrix [8]. Due to the requirements for producing such EL device we used a GPTMS/PEDOT:PSS (90/10\%wt of GPTMS/PEDOT:PSS) material, which is below the percolation point. The current vs. voltage and luminance vs. voltage curves, in 

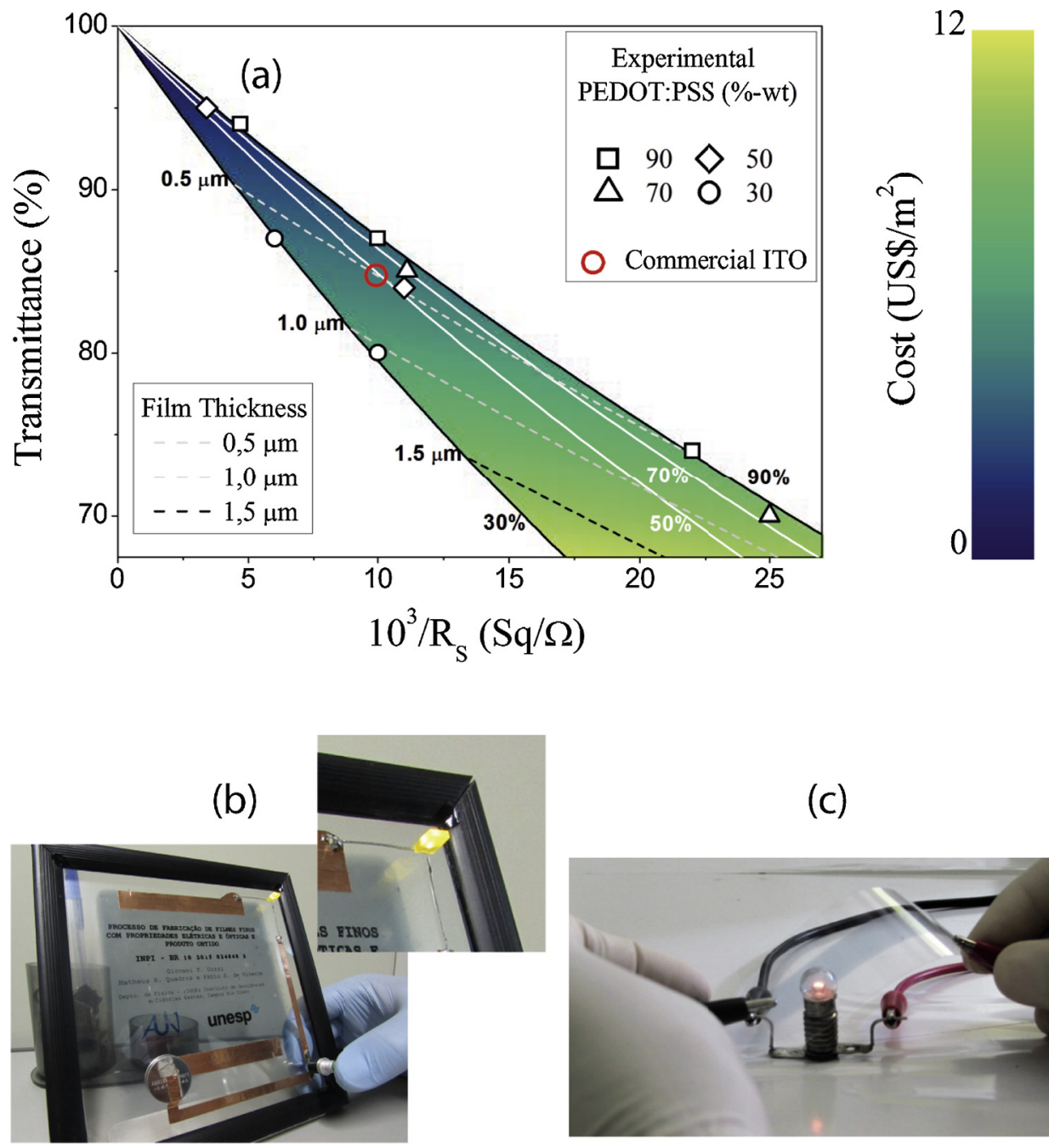

(c)

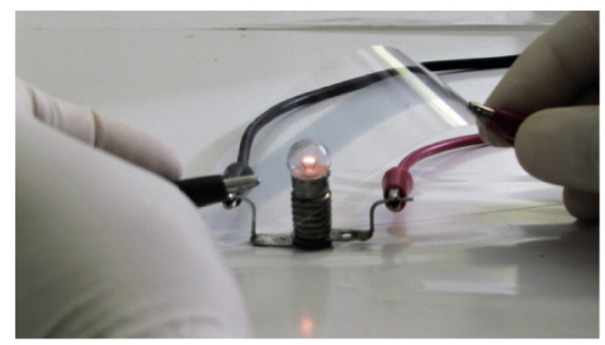

Fig. 3. (a) Figure of merit for transparent and conductive films produced with GPTMS/PEDOT:PSS mixtures; (b) picture showing the proof of concept using a series circuit with a LED, two batteries ( $3 \mathrm{~V}$ each) and the transparent film as resistor; (c) picture showing the flexibility of a film coated over PET substrate.

Fig. 4(a), show that the device produced using ITO and gold as electrodes, with a $140 \mu \mathrm{m}$ thick active layer and active area of $0.85 \mathrm{~cm}^{2}$, operates on both polarities, with turn-on voltages in the 30-36 V, which is significantly low, considering the film thickness (electric field of $2.6 \times 10^{5} \mathrm{~V} / \mathrm{m}$ ). These characteristics are quite similar to that published on a similar light-emitting device [8,37-43]. The device luminance reached $2500 \mathrm{~cd} / \mathrm{m}^{2}$ and a luminous efficacy of $26 \mathrm{~cd} / \mathrm{A}$, as can be seen in Fig. 4(a) and (b). As illustrated by Fig. 4(c) and 4(d), the device emitted green light $(\lambda=535 \mathrm{~nm})$, producing a CIE 1931 Illuminant $\mathrm{E}$ coordinates of $\mathrm{x}=0.222$ and $\mathrm{y}=0.692$ and a color purity of $85 \%$. Usually devices produced with light-emitting composites comprising inorganic microparticles exhibit maximum luminance of $50 \mathrm{~cd} /$ $\mathrm{m}^{2}[37,38]$ and $100 \mathrm{~cd} / \mathrm{m}^{2}[8]$, and it is necessary a complex device structure to achieve numbers close to $10^{3} \mathrm{~cd} / \mathrm{m}^{2}$ [39]. Devices with maximum luminance in the range $10^{3}-10^{4} \mathrm{~cd} / \mathrm{m}^{2}$ were already produced using ultrathin films of composites comprising nanoparticles [40-43]. Although the light intensity is fairly high on these devices, their luminous efficacy are very low, normally not higher than $10 \mathrm{~cd} / \mathrm{A}$.

We have also explored the GPTMS/PEDOT:PSS films as active material in an electrochromic device. PEDOT:PSS is known as a mixed conductor, being able to support both electronic and ionic conduction. A major application of this characteristic is the use of PEDOT:PSS as the active layer of organic electrochemical transistor (OECTs) as well as an electrochromic device $[44,45]$. When ions enter the materials, polaronic states are formed within the material's bandgap changing its optical properties, causing a change on the film coloring. The advantage of PEDOT:PSS over other electrochromic materials is due to its good response time, great color contrast and, more importantly, its ability to be processed from a water emulsion. The electrochromic device was produced by coating a layer of GPTMS/PEDOT:PSS (10/90\%-wt) on top of an ITO electrode. The film was immersed in an electrolyte solution (100 mM NaCl). An Ag/AgCl reference electrode was placed in the solution and a potential was applied between the $\mathrm{Ag} / \mathrm{AgCl}$ and the ITO electrode. Fig. 5(a) shows the absorption spectra for two voltages. With a null voltage between the ITO and the reference electrode, the GPTMS/ PEDOT:PSS (10/90\%-wt) is barely transparent. However, when a positive voltage is applied to the $\mathrm{Ag} / \mathrm{AgCl}, \mathrm{Na}^{+}$ions penetrates the composite, changing its absorption properties, as can be seen by the absorption peak for $+1 \mathrm{~V}$ (solid line). Fig. 5 (b) and (c) are real pictures of the experimental setup when polarizing the film with $0 \mathrm{~V}$ and $+1 \mathrm{~V}$ respectively: the latter shows a dark-blue color, consistently with the absorption spectrum.

\section{Conclusion}

In summary, we demonstrated a new strategy to produce stable PEDOT:PSS films to be used as semitransparent electrodes, active matrix in light-emitting device and electrochromic devices. The film conductivity measurements show a clear indicative of a phase separation of the GPTMS and PEDOT:PSS regions occurring in the nanoscale regime, 

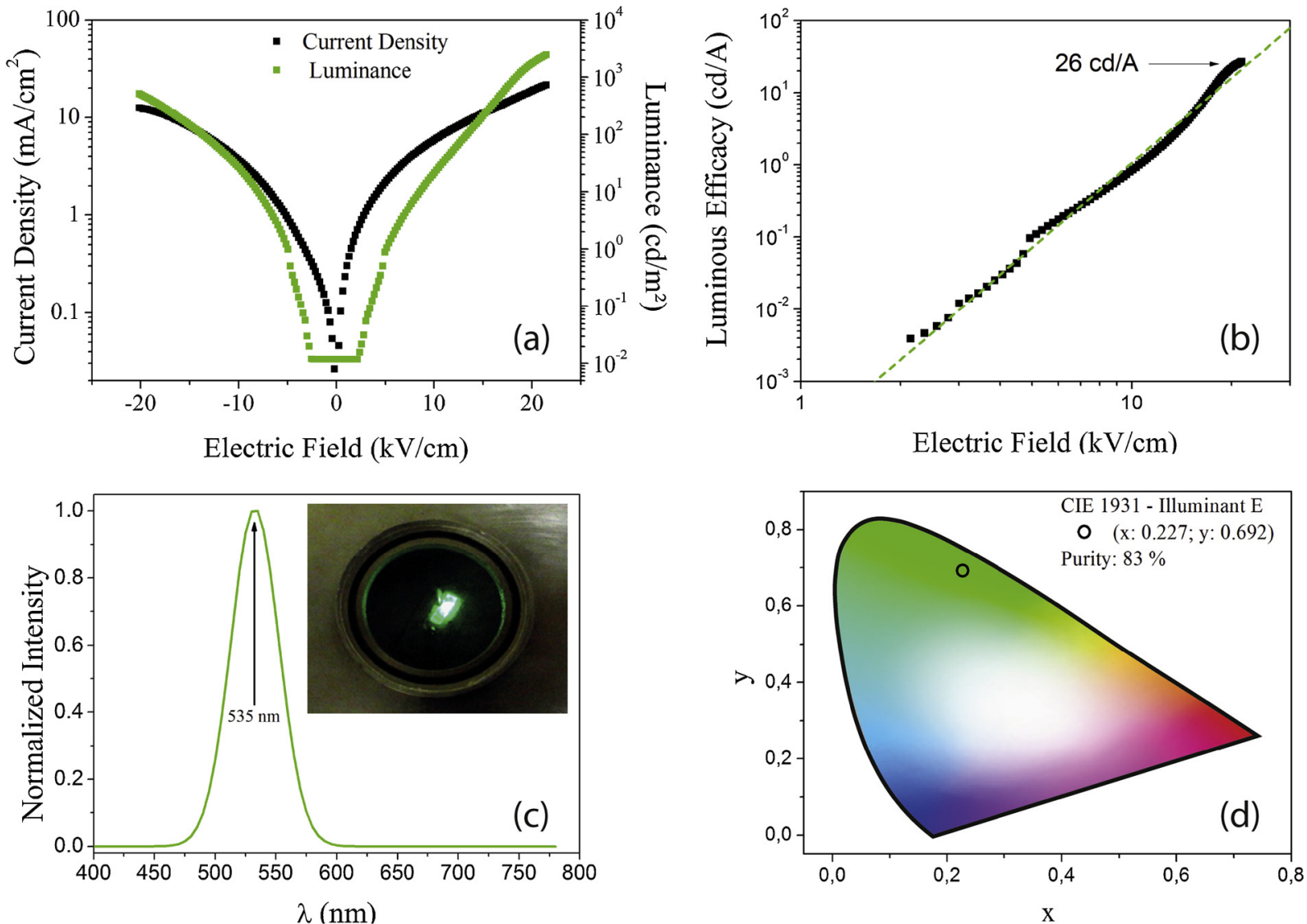

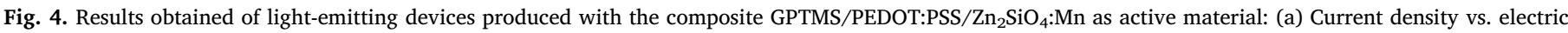

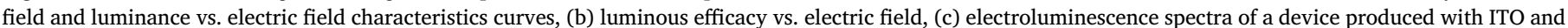
Gold electrodes; (d) CIE color diagram.

i.e., the films are homogeneous in macroscopic and microscopic scales. As consequence of the nanoscale phase separation, films produced with less than 40\%-wt of PEDOT:PSS exhibits an exponential dependence on the PEDOT:PSS concentration, which is characteristic of systems below the percolation limit of the conductive phase. On the other hand, films produced with concentrations above $40 \%$-wt of PEDOT:PSS, presented a linear dependence of the conductivity on the conductive phase concentration, evidencing the achievement of the percolation limit. The electrical conductivity of the mixture varied between $2 \mathrm{~S} / \mathrm{cm}(10 \%-\mathrm{wt}$ of PEDOT:PSS) and $600 \mathrm{~S} / \mathrm{cm}$ (90\%-wt of PEDOT:PSS). As proof of concept, we applied those composites as conductive matrix to a phosphors-based electroluminescent device as well as to electrochromic systems.
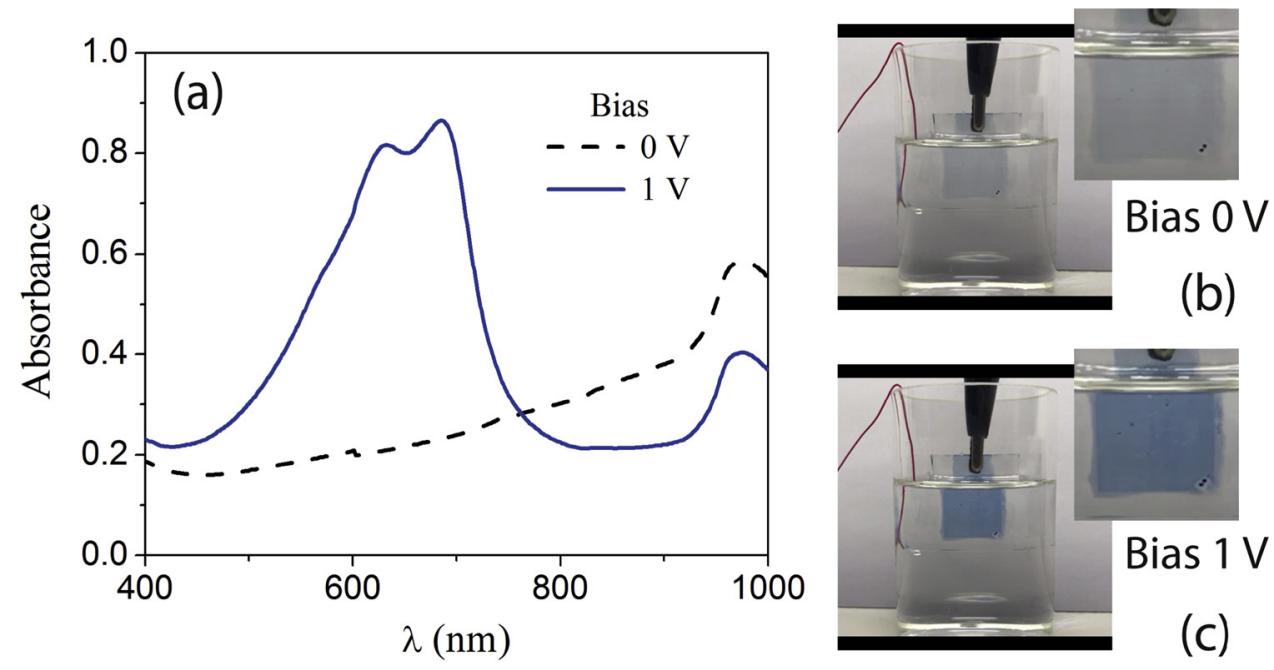

Fig. 5. Results obtained from an electrochromic device produced with GPTMS/PEDOT:PSS as active material and water solution of NaCl (100 mM) as electrolyte: (a) device absorbance spectra for $0 \mathrm{~V}$ and $1 \mathrm{~V}$ bias; (b) picture of the device biased at $0 \mathrm{~V}$; (c) picture of the device biased at $1 \mathrm{~V}$. 


\section{Acknowledgments}

R. Colucci acknowledges financial support from Coordenação de Aperfeiçoamento de Pessoal de Nível Superior (CAPES) and F.H. Feres acknowledges financial support from the Fundação de Amparo à Pesquisa do Estado de São Paulo (FAPESP - Grant number 2015/250699). G. C Faria acknowledges financtial support from the Conselho Nacional de Desenvolvimento Científico e Tecnológico (CNPq - Grant number 312025/2016-5). Authors also acknowledge the INCT/INEO/ FAPESP/CNPq for financial support through project numbers 2008/ 57706-4 and 573762/2008-2 and to the Brazilian Synchrotron Light Laboratory (LNLS) for projects 20160516 and 20170053.

\section{Appendix A. Supplementary data}

Supplementary material related to this article can be found, in the online version, at doi:https://doi.org/10.1016/j.synthmet.2018.04. 002.

\section{References}

[1] S. Ahmad, Organic semiconductors for device applications: current trends and future prospects, J. Polym. Eng. 34 (2014) 279-338, http://dx.doi.org/10.1515/ polyeng-2013-0267.

[2] A. Facchetti, $\pi$-Conjugated polymers for organic electronics and photovoltaic cell applications, Chem. Mater. 23 (2011) 733-758, http://dx.doi.org/10.1021/ $\mathrm{cm} 102419 \mathrm{z}$

[3] T. Sekitani, T. Someya, Stretchable organic integrated circuits for large-area electronic skin surfaces, Mrs Bull. 37 (2012) 236-245, http://dx.doi.org/10.1557/Mrs 2012.42.

[4] D.E. Anagnostou, A.A. Gheethan, A.K. Amert, K.W. Whites, A direct-write printed antenna on paper-based organic substrate for flexible displays and WLAN applications, IEEE/OSA J. Disp. Technol. 6 (2010) 558-564, http://dx.doi.org/10.1109/ JDT.2010.2045474.

[5] J.M. Nassar, M.D. Cordero, A.T. Kutbee, M.A. Karimi, G.A.T. Sevilla, A.M. Hussain, A. Shamim, M.M. Hussain, Paper skin multisensory platform for simultaneous environmental monitoring, Adv. Mater. Technol. (2016), http://dx.doi.org/10.1002/ admt.201600004 n/a-n/a.

[6] A.R. Brown, D.D.C. Bradley, J.H. Burroughes, R.H. Friend, N.C. Greenham, P.L. Burn, A.B. Holmes, A.M. Kraft, Light-emitting diodes based on conjugated polymers, Conduct. Polym. Their Appl. IEE Colloq. 347 (1992) 2/1-2/4, http://dx. doi.org/10.1038/347539a0.

[7] O. Pei, G. Yu, C. Zhang, A.J. Heeger, Polymer light-emitting electrochemical cells, Science 80 (269) (1995) 1086-1088.

[8] D.L. Chinaglia, G. Gozzi, T.F. Schmidt, L.F. Santos, D.T. Balogh, O.N. Oliveira Jr, R.M. Faria, Fabrication of novel light-emitting devices based on green-phosphor/ conductive-polymer composites, Philos. Mag. Lett. 87 (2007), http://dx.doi.org/10. 1080/09500830701203149.

[9] T. Karasawa, Y. Miyata, Electrical and optical properties of indium tin oxide thin films deposited on unheated substrates by d.c. reactive sputtering, Technology 223 (1993) 135-139, http://dx.doi.org/10.1016/0040-6090(93)90737-A.

[10] A.K. Kulkarni, K.H. Schulz, T.S. Lim, M. Khan, Dependence of the sheet resistance of indium-tin-oxide thin films on grain size and grain orientation determined from $\mathrm{x}$ ray diffraction techniques, Thin Solid Films 345 (1999) 273-277, http://dx.doi.org/ 10.1016/S0040-6090(98)01430-8.

[11] I.D. Parker, Carrier tunneling and device characteristics in polymer light-emitting diodes, J. Appl. Phys. 75 (1994) 1656-1666, http://dx.doi.org/10.1063/1.356350.

[12] M.T. Bernius, M. Inbasekaran, J. O'Brien, W. Wu, Progress with light-emitting polymers, Adv. Mater. 12 (2000) 1737-1750, http://dx.doi.org/10.1002/1521 4095(200012)12:23<1737::AID-ADMA1737>3.0.CO;2-N

[13] D. Hohertz, J. Gao, How electrode work function affects doping and electroluminescence of polymer light-emitting electrochemical cells, Adv. Mater. 20 (2008) 3298-3302, http://dx.doi.org/10.1002/adma.200800068.

[14] G. Gozzi, D.L. Chinaglia, T.F. Schmidt, O.N. Oliveira, Charge injection in an LED with a hybrid composite as the emissive layer, Mater. Sci. Eng. C. 31 (2011) 969-974, http://dx.doi.org/10.1016/j.msec.2011.02.022.

[15] P. Matyba, H. Yamaguchi, M. Chhowalla, N.D. Robinson, L. Edman, Flexible and metal-free light-emitting electrochemical cells based on graphene and PEDOT-PSS as the electrode materials, ACS Nano. 5 (2011) 574-580, http://dx.doi.org/10. 1021/Nn102704h.

[16] J. Liang, L. Li, X. Niu, Z. Yu, Q. Pei, Fully solution-based fabrication of flexible lightemitting device at ambient conditions, J. Phys. Chem. C. 117 (2013) 16632-16639, http://dx.doi.org/10.1021/jp405569q.

[17] A. Sandström, A. Asadpoordarvish, J. Enevold, L. Edman, Spraying light: ambientair fabrication of large-area emissive devices on complex-shaped surfaces, Adv. Mater. 26 (2014) 4975-4980, http://dx.doi.org/10.1002/adma.201401286.

[18] P.H. Wöbkenberg, G. Eda, D.-S. Leem, J.C. de Mello, D.D.C. Bradley, M. Chhowalla, T.D. Anthopoulos, Reduced graphene oxide electrodes for large area organic elec tronics, Adv. Mater. 23 (2011) 1558-1562, http://dx.doi.org/10.1002/adma.
201004161.

[19] S. Pang, Y. Hernandez, X. Feng, K. Müllen, Graphene as transparent electrode material for organic electronics, Adv. Mater. 23 (2011) 2779-2795, http://dx.doi. org/10.1002/adma.201100304.

[20] J.O. Hwang, J.S. Park, D.S. Choi, J.Y. Kim, S.H. Lee, K.E. Lee, Y.H. Kim, M.H. Song, S. Yoo, S.O. Kim, Workfunction-tunable, N-doped reduced graphene transparent electrodes for high-performance polymer light-emitting diodes, ACS Nano. 6 (2012) 159-167, http://dx.doi.org/10.1021/nn203176u.

[21] D.S. Hecht, L. Hu, G. Irvin, Emerging transparent electrodes based on thin films of carbon nanotubes, graphene, and metallic nanostructures, Adv. Mater. 23 (2011) 1482-1513, http://dx.doi.org/10.1002/adma.201003188.

[22] A. Benyounes, N. Abbas, M. Hammi, Y. Ziat, A. Slassi, N. Zahra, Fabrication and characterization of novel transparent conducting oxide N-CNT doped ZnO for photovoltaic applications, Appl. Phys. A - Matter. 124 (90) (2018), http://dx.doi. org/10.1007/s00339-017-1528-7.

[23] C. Celle, A. Cabos, T. Fontecave, B. Laguitton, A. Benayad, L. Guettaz, N. Pélissier, V.H. Nguyen, D. Bellet, D. Muñoz-Rojas, J. Simonat, Oxidation of copper nanowire based transparent electrodes in ambient conditions and their stabilization by encapsulation: application to transparent film heaters, Int. J. Biomed. Nanosci. 29 (2018) 085701, http://dx.doi.org/10.1088/1361-6528/aaa48e.

[24] W. Li, Q. Yu, Y. Yu, Highly efficient and low cost friction method for producing 2D nanomaterials on poly(ethylene terephthalate) and their applications for commercial flexible electronics, Transl. Mater. Res. 4 (2017) 035001, http://dx.doi.org/10 1088/2053-1613/aa87d9.

[25] D.H. Shin, J.M. Kim, S.W. Seo, J.H. Kim, S. Kim, S. Choi, Si heterojunction solar cells employing graphene transparent conductive electrodes co-doped with gold chlorides and silver nanowire, J. Alloy. Compd. 726 (2017) 1047-1052, http://dx. doi.org/10.1016/j.jallcom.2017.08.096.

[26] H. Lee, Y. Song, T.K. An, W. Choi, S. Kim, Ultrasmooth transparent conductive hybrid films of reducedgraphene oxide and single-walled carbon nanotube by ultrasonic spraying, Synthetic Met. 221 (2016) 340-344, http://dx.doi.org/10.1016/ j.synthmet.2016.10.012

[27] B.W.N.H. Hemasiri, J. Kim, J. Lee, Synthesis and characterization of graphene/ITO nanoparticle hybrid transparent conducting electrode, Nano-Micro Lett. 10 (2018) 18, http://dx.doi.org/10.1007/s40820-017-0174-0.

[28] O. Carr, G. Gozzi, L.F. Santos, R.M. Faria, D.L. Chinaglia, Analysis of the electrical and optical properties of PEDOT:PSS/PVA blends for low-cost and high-performance organic electronic and optoelectronic devices, Transl. Mater. Res. 2 (2015) 15002, http://dx.doi.org/10.1088/2053-1613/2/1/015002.

[29] B. Lebeau, P. Innocenzi, Hybrid materials for optics and photonics, Chem. Soc. Rev. 40 (2011) 886-906, http://dx.doi.org/10.1039/c0cs00106f.

[30] D. Isin, N. Kayaman-Apohan, A. Güngör, Preparation and characterization of uvcurable epoxy/silica nanocomposite coatings, Prog. Org. Coatings. 65 (2009) 477-483, http://dx.doi.org/10.1016/j.porgcoat.2009.04.007.

[31] S. Zhang, P. Kumar, A.S. Nouas, L. Fontaine, H. Tang, F. Cicoira, Solvent-induced changes in PEDOT:PSS films for organic electrochemical transistors, Apl. Mater. 3 (2015) 014911, http://dx.doi.org/10.1063/1.4905154.

[32] M. Sessolo, D. Khodagholy, J. Rivnay, F. Maddalena, M. Gleyzes, E. Steidl, B. Buisson, G.G. Malliaras, Easy-to-Fabricate conducting polymer microelectrode arrays, Adv. Mater. 25 (2013) 2135-2139, http://dx.doi.org/10.1002/adma. 201204322.

[33] C. Duc, A. Vlandas, G.G. Malliaras, V. Senez, Wettability of PEDOT:PSS films, Soft Matter. 12 (2016) 5146-5153, http://dx.doi.org/10.1039/c6sm00599c.

[34] D. Mantione, I. del Agua, W. Schaafsma, M. ElMahmoudy, I. Uguz, A. SanchezSanchez, H. Sardon, B. Castro, G.G. Malliaras, D. Mecerreyes, Low-Temperature cross-linking of PEDOT:PSS films using divinylsulfone, ACS Appl. Mater. Inter. 9 (2017) 18254-18262, http://dx.doi.org/10.1021/acsami.7b02296.

[35] J. Ouyang, Q. Xu, C.W. Chu, Y. Yang, G. Li, J. Shinar, On the mechanism of conductivity enhancement in poly(3,4- ethylenedioxythiophene):poly(styrene sulfonate) film through solvent treatment, Polymer (Guildf) 45 (2004) 8443-8450, http://dx.doi.org/10.1016/j.polymer.2004.10.001.

[36] A. Hakansson, S. Han, S. Wang, J. Lu, S. Braun, M. Fahlman, M. Berggren, X. Crispin, S. Fabiano, Effect of (3-Glycidyloxypropyl)trimethoxysilane (GOPS) on the electrical properties of PEDOT:PSS films, J. Polym. Sci. Pol. Phy. 55 (2017) 814-820, http://dx.doi.org/10.1002/polb.24331.

[37] S. Jun, Y. Kim, B. Ju, J. Kim, Extremely flexible, transparent, and strain-sensitive electroluminescent device based on ZnS:Cu-polyvinyl butyral composite and silver nanowires, Appl. Surf. Sci. 429 (2018) 144-150, http://dx.doi.org/10.1016/j. apsusc. 2017.07.286.

[38] B.K. Gupta, S. Singh, G. Kedawat, Kanika P. Kumar, A.K. Gangwar, T.N. Narayanan, A.A. Marti, R. Vajtai, P.M. Ajayan, A novel electroluminescent device based on a reduced graphene oxide wrapped phosphor $(\mathrm{ZnS}: \mathrm{Cu}, \mathrm{Al})$ and hexagonal-boron $\mathrm{ni}$ tride for high-performance luminescence, Nanoscale 9 (2017) 5002, http://dx.doi. org/10.1039/c6nr09302g.

[39] H. Shim, B. Allabergenov, J. Kim, H.Y. Noh, H. Lyu, M. Lee, B. Choi, Highly brigh flexible electroluminescent devices with retroreflective electrodes, Adv. Mater. Technol. 2 (2017) 1700040, http://dx.doi.org/10.1002/admt.201700040.

[40] S.G.R. Bade, X. Shan, P.T. Hoang, J. Li, T. Geske, L. Cai, Q. Pei, C. Wang, Z. Yu, Stretchable light-emitting diodes with organometal-Halide-perovskite-Polymer composite emitters, Adv. Mater. 29 (2017) 1607053, http://dx.doi.org/10.1002/ adma. 201607053.

[41] C. Huang, S. Huang, M.M. Liu, Hybridization of $\mathrm{CsPbBr}_{1.5} \mathrm{I}_{1.5}$ perovskite quantum dots with 9,9-dihexylfluorene co-oligomer for white electroluminescence, Org. Electron. 44 (2017) 6-10, http://dx.doi.org/10.1016/j.orgel.2017.01.042.

[42] X. Ji, X. Peng, Y. Lei, Z. Liu, X. Yang, Multilayer light emitting devices with organometal halide perovskite: polymer composite emission layer: the relationship of 
device performance with the compositions of emission layer and device config urations, Org. Electron. 43 (2017) 167-174, http://dx.doi.org/10.1016/j.orgel. 2017.01.024.

[43] M. Tu, Y. Su, R. Chen, Hybrid light-emitting diodes from anthracene-contained polymer and CdSe/ZnS core/shell quantum dots, Nanoscale Res. Lett. 9 (611) (2014), http://dx.doi.org/10.1186/1556-276X-9-611.
[44] G.C. Faria, D.T. Duong, A. Salleo, On the transient response of organic electrochemical transistors, Org. Electron. Phys., Mater. Appl. 45 (2017) 215-221, http:// dx.doi.org/10.1016/j.orgel.2017.03.021.

[45] G.C. Faria, D.T. Duong, A. Salleo, C.A. Polyzoidis, S. Logothetidis, J. Rivnay, R. Owens, G.G. Malliaras, Organic electrochemical transistors as impedance biosensors, Mrs Commun. 4 (2014) 189-194, http://dx.doi.org/10.1557/mrc.2014.35. 